\title{
Nationwide Inpatient Sample and National Surgical Quality Improvement Program Give Different Results in Hip Fracture Studies
}

\author{
Daniel D. Bohl MPH, Bryce A. Basques BS, \\ Nicholas S. Golinvaux BA, Michael R. Baumgaertner MD, \\ Jonathan N. Grauer MD
}

Received: 17 December 2013/Accepted: 26 February 2014/Published online: 11 March 2014

(C) The Association of Bone and Joint Surgeons (R 2014

\begin{abstract}
Background National databases are being used with increasing frequency to conduct orthopaedic research. However, there are important differences in these databases, which could result in different answers to similar questions; this important potential limitation pertaining to database research in orthopaedic surgery has not been adequately explored.

Questions/purposes The purpose of this study was to explore the interdatabase reliability of two commonly used national databases, the Nationwide Inpatient Sample (NIS) and the National Surgical Quality Improvement Program (NSQIP), in terms of (1) demographics; (2) comorbidities; and (3) adverse events. In addition, using the NSQIP database, we identified (4) adverse events that had a higher prevalence after rather than before discharge, which has important implications for interpretation of studies conducted in the NIS.

Methods A retrospective cohort study of patients undergoing operative stabilization of transcervical and intertrochanteric hip fractures during 2009 to 2011 was performed in the NIS and NSQIP. Totals of 122,712 and 5021 patients were included

Each author certifies that he or she, or a member of his or her immediate family, has no funding or commercial associations (eg, consultancies, stock ownership, equity interest, patent/licensing arrangements, etc) that might pose a conflict of interest in connection with the submitted article.

All ICMJE Conflict of Interest Forms for authors and Clinical Orthopaedics and Related Research editors and board members are on file with the publication and can be viewed on request.
\end{abstract}

D. D. Bohl, B. A. Basques, N. S. Golinvaux,

M. R. Baumgaertner, J. N. Grauer ( $\square)$

Department of Orthopaedics and Rehabilitation, Yale School of

Medicine, 800 Howard Avenue, New Haven, CT 06510, USA

e-mail: jonathan.grauer@yale.edu from the NIS and NSQIP, respectively. Age, sex, fracture type, and lengths of stay were compared. Comorbidities common to both databases were compared in terms of more or less than twofold difference between the two databases. Similar comparisons were made for adverse events. Finally, adverse events that had a greater postdischarge prevalence were identified from the NSQIP database. Tests for statistical difference were thought to be of little value given the large sample size and the resulting fact that statistical differences would have been identified even for small, clinically inconsequential differences resulting from the associated high power. Because it is of greater clinical importance to focus on the magnitude of differences, the databases were compared by absolute differences. Results Demographics and hospital lengths of stay were not different between the two databases. In terms of comorbidities, the prevalences of nonmorbid obesity, coagulopathy, and anemia in found in the NSQIP were more than twice those in the NIS; the prevalence of peripheral vascular disease in the NIS was more than twice that in the NSQIP. Four other comorbidities had prevalences that were not different between the two databases. In terms of inpatient adverse events, the frequencies of acute kidney injury and urinary tract infection in the NIS were more than twice those in the NSQIP. Ten other inpatient adverse events had frequencies that were not different between the two databases. Because it does not collect data after patient discharge, it can be implied from the NSQIP data that the NIS does not capture more than $1 / 2$ of the deaths and surgical site infections occurring during the first 30 postoperative days.

Conclusions This study shows that two databases commonly used in orthopaedic research can identify similar populations of operative patients but may generate very different results for specific commonly studied comorbidities and adverse events. The NSQIP identified higher rates 
of morbid obesity, coagulopathy, and anemia. The NIS identified higher rates of peripheral vascular disease, acute kidney injury, and urinary tract infection.

Level of Evidence Level II, prognostic study. See the Instructions for Authors for a complete description of levels of evidence.

\section{Introduction}

National databases are being used with increasing frequency to conduct orthopaedic research. Two of the most commonly used databases are the Nationwide Inpatient Sample (NIS) [4] and the American College of Surgeons National Surgical Quality Improvement Program (NSQIP) $[2,8]$. The number of orthopaedic surgery publications that cite these databases has increased dramatically in the last several years (Fig. 1) [12]. For example, recent studies using the NIS have investigated the effects of comorbidities on hospitalization costs after hip fracture [13], risk factors for elderly patients undergoing total joint arthroplasty [5], and perioperative morbidity and mortality after bilateral THAs [17]. Similarly, recent studies using the NSQIP have investigated risk factors for morbidity and mortality after knee arthroscopy [11], risk for morbidity and mortality after hip fracture surgery [16], and factors independently associated with complications and length of stay after hip arthroplasty [14].

Any study has inherent limitations and biases that stem from the type and quality of data on which it is based. The large numbers of patient records available in national databases do not make studies using them immune to such

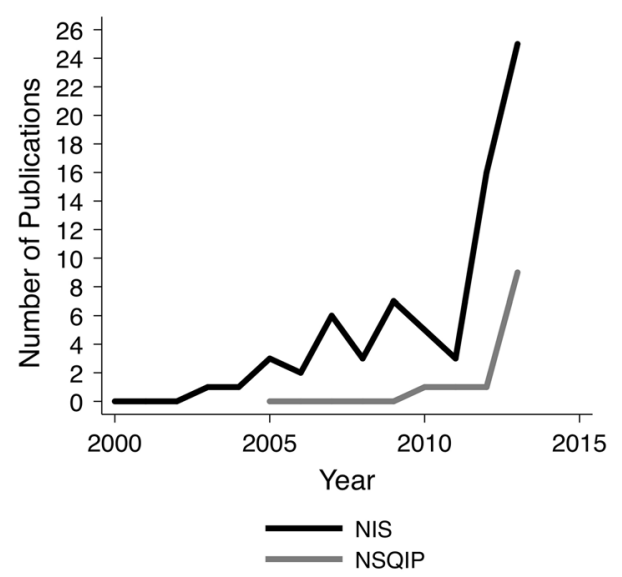

Fig. 1 The numbers of orthopaedic surgery publications using the NIS and NSQIP per year since 2000 based on a PubMed search of the 41 orthopaedic journals identified by Moverley et al. [12] for the terms "Nationwide Inpatient Sample" or "National Surgical Quality Improvement Program" on November 19, 2013 are shown. Only original research studies were included. In total, there were 72 studies using the NIS and 12 using the NSQIP. issues. Given the increasing use of national databases for orthopaedic research, it is important to understand the differences between databases, because these differences may result in different answers to similar questions, depending on which database is used. There are differences between the NIS and NSQIP that potentially could lead to generation of different answers (Table 1).

We aimed to investigate these issues, exploring the interdatabase reliability of the NIS and NSQIP with respect to operative stabilization of hip fractures - a frequent procedure in orthopaedic surgery, one that is commonly studied, and one for which early outcomes are particularly important. We compared the databases in terms of (1) demographics; (2) comorbidities; and (3) adverse events. In addition, using the NSQIP database, we identified (4) adverse events that had a greater prevalence after rather than before discharge, which has important implications for the interpretation of studies conducted using the NIS.

\section{Materials and Methods}

A retrospective cohort study of patients with hip fractures undergoing operative stabilization during 2009 to 2011 was performed using the NIS and NSQIP databases. From both databases, we initially identified all cases of transcervical fractures (ICD-9 code 820.0x) and intertrochanteric fractures (ICD-9 code 820.21). From these, we selected cases associated with a procedure code indicating operative stabilization: from the NIS, cases associated with an ICD-9 procedure code of $78.55,79.15,79.35,81.51$, or 81.52 ; from the NSQIP, cases associated with a CPT code of 27125, 27130, 27235, 27236, 27244, or 27245. Subtrochanteric hip fractures are less common and more variable in presentation and outcome and thus were not included in our study.

From the NIS and NSQIP, respectively, 122,712 and 5021 operatively stabilized patients with hip fractures were identified and constitute the study population.

To make patients less identifiable, NSQIP reports all patients older than 90 years as 90 years old. To make data comparable, we similarly considered patients in the NIS who were older than 90 years to be 90 years old. The NIS and NSQIP record and directly report total hospital length of stay in calendar days.

Eight commonly studied comorbidities for which the presence could be identified in the NIS and NSQIP were selected (Appendix 1) and compared between databases. Twelve commonly studied adverse events for which the occurrence could be identified in the NIS and NSQIP were selected (Appendix 2) and compared between databases.

Tests for statistical difference were thought to be of little value given the large sample size and the resulting fact that 
Table 1. Differences between the NIS and NSQIP

\begin{tabular}{llc}
\hline Factor & NIS & NSQIP \\
\hline Identification of patients & Retrospective, a sample of inpatient discharges & $\begin{array}{c}\text { Prospective, a sample of patients } \\
\text { identified at participating institutions } \\
\text { Current procedure terminology codes }\end{array}$ \\
Comorbidity and adverse event data & $\begin{array}{c}\text { International classification of disease, } 9^{\text {th }} \text { revision } \\
\text { procedure codes } \\
\text { Reimbursement data in the form of international } \\
\text { classification of disease, } 9^{\text {th }} \text { revision codes }\end{array}$ & $\begin{array}{c}\text { Directed review of medical records by } \\
\text { specially trained surgical clinical } \\
\text { reviewers, with routine auditing to } \\
\text { ensure quality }\end{array}$ \\
Time range of data collected & Inpatient only & $\begin{array}{c}\text { Inpatient and outpatient up to the } 30^{\text {th }} \\
\text { postoperative day }\end{array}$ \\
\hline
\end{tabular}

NIS = National Inpatient Sample; NSQIP = National Surgical Quality Improvement Program.

statistical differences would have been identified even for small, clinically inconsequential differences resulting from the associated high power. Because it is of greater clinical importance to focus on the magnitude of differences, the databases were compared by absolute differences.

First, age was compared in terms of percentiles. Second, sex and fracture type were compared by categorical distribution. Third, length of stay was compared in terms of percentiles. Finally, comorbidity and adverse event rates were compared. To make the adverse event rate comparisons most direct, given that NSQIP captures events before and after discharge (although the NIS captures only inpatient adverse events), adverse events in the NSQIP were categorized as having occurred before discharge (including any time on the day of discharge) or after discharge (shown on graphs but not able to be directly compared with the NIS). Events in NSQIP occurring before discharge were directly compared with events occurring in the NIS. For the comorbidity and adverse event comparisons, comorbidities and adverse events were organized into three groups: (1) the rate in NSQIP was more than twice that in the NIS; (2) the rate in the NIS was more than twice that in the NSQIP; and (3) neither of the prior conditions were fulfilled (the rates had less than a twofold difference).

\section{Results}

The demographics in the two databases were not different between the two populations of operatively stabilized patients with hip fractures. The age distributions for the NIS and NSQIP were similar with differences among the 25th, 50th, and 75th percentiles of no more than 1 year (Fig. 2). Categorical distributions of sex and type of fracture also were similar with differences no more than one percentage point (Table 2). The length of stay distributions were not different. The numbers of days after surgery at which $75 \%, 50 \%$, and $25 \%$ of patients remained in the hospital were identical (Fig. 3).
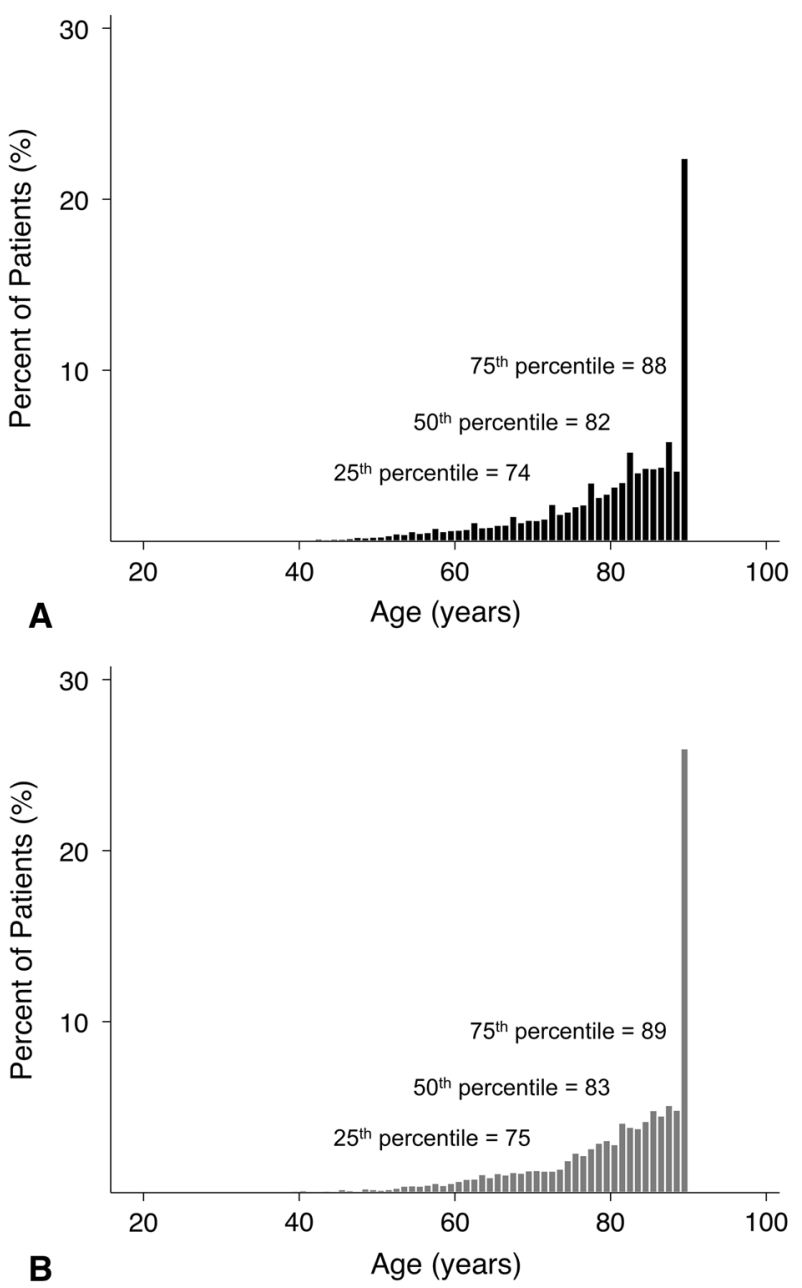

Fig. 2A-B The distributions of patient age for the (A) NIS and (B) NSQIP are shown. The 25th (74 and 75 years), 50th (82 and 83 years), and 75th ( 88 and 89 years) percentiles were within 1 year of each other. To make patients less identifiable, the NSQIP reports all patients older than 90 years as 90 years; to make data comparable, we treated patients in the NIS who were older than 90 years as 90 years. The regularly spaced spikes in the distributions are the result of some states' requirements that age be rounded to make data less identifiable. 
Table 2. Demographics*

\begin{tabular}{|c|c|c|c|c|}
\hline \multirow[t]{2}{*}{ Demographic } & \multicolumn{2}{|l|}{ NIS } & \multicolumn{2}{|l|}{ NSQIP } \\
\hline & Number & Percent & Number & Percent \\
\hline Total & 122,712 & 100.0 & 5021 & 100.0 \\
\hline \multicolumn{5}{|l|}{ Sex } \\
\hline Male & 36,044 & 29.4 & 1505 & 30.0 \\
\hline Female & 86,668 & 70.6 & 3516 & 70.0 \\
\hline \multicolumn{5}{|l|}{ Fracture type } \\
\hline Transcervical & 45,185 & 36.8 & 1896 & 37.8 \\
\hline Intertrochanteric & 77,527 & 63.2 & 3125 & 62.2 \\
\hline
\end{tabular}

* Differences between the NIS and NSQIP were no more than one percentage point in any case; NIS = Nationwide Inpatient Sample; NSQIP = National Surgical Quality Improvement Program.
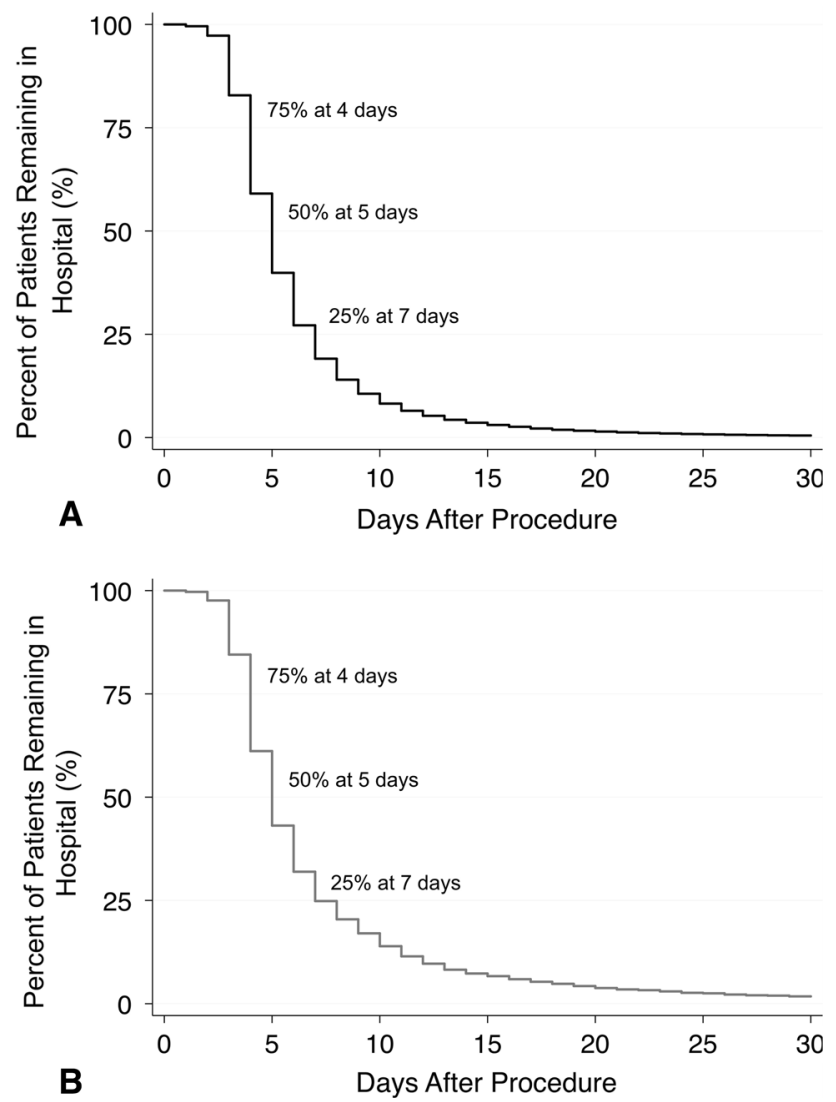

Fig. 3A-B Survival curves for length of stay for the (A) NIS and (B) NSQIP are shown. The numbers of days after the procedure at which $75 \%$ (4 and 4 days), 50\% (5 and 5 days), and 25\% (7 and 7 days) of patients remained in the hospital were identical.

Despite yielding demographically similar populations, prevalences of comorbidities differed in the two databases (Fig. 4), in which three distinct groups of relative prevalence were identified. First, the prevalence documented in the NSQIP was more than twice that in the NIS for nonmorbid obesity (BMI, $30-40 \mathrm{~kg} / \mathrm{m}^{2}$ ), coagulopathy, and anemia. Second, the prevalence documented in the NIS was more than twice that in the NSQIP for peripheral vascular disease. Third, the prevalences documented in the two databases were within a twofold difference for morbid obesity (BMI $>40 \mathrm{~kg} / \mathrm{m}^{2}$ ), chronic obstructive pulmonary disease, diabetes, and hypertension.

Similarly, we found certain adverse events rates greater in the NIS compared with the NSQIP before discharge (Fig. 5). First, the frequency documented in the NIS was more than twice the frequency documented in the NSQIP before discharge for acute kidney injury and urinary tract infection. Second, the frequency documented in the NSQIP before discharge was within a twofold difference of the frequency documented in the NIS for surgical site infection, cardiac arrest, stroke, pulmonary embolism, deep vein thrombosis, sepsis, mortality, myocardial infarction, postoperative intubation, and pneumonia.

The rate of adverse events documented in the NSQIP after discharge and within 30 days of surgery actually exceeded that documented in the NSQIP before discharge for surgical site infection and mortality (Fig. 5).

\section{Discussion}

National databases are increasingly being used as data sources for orthopaedic surgery research. Conclusions are being drawn from well-powered, well-constructed studies. However, questions regarding the validity and consistency of such conclusions have not been fully addressed. We investigated the interdatabase reliability of the NIS and NSQIP.

Our study has two main limitations. First, it lacks patient-identifiable data with which to directly compare results on a patient-by-patient basis for a genuine measure of validity. As a result, it can identify differences between the databases, but it cannot verify which database is performing more accurately. Second, there is the potential for bias resulting from comparison of nonequivalent 


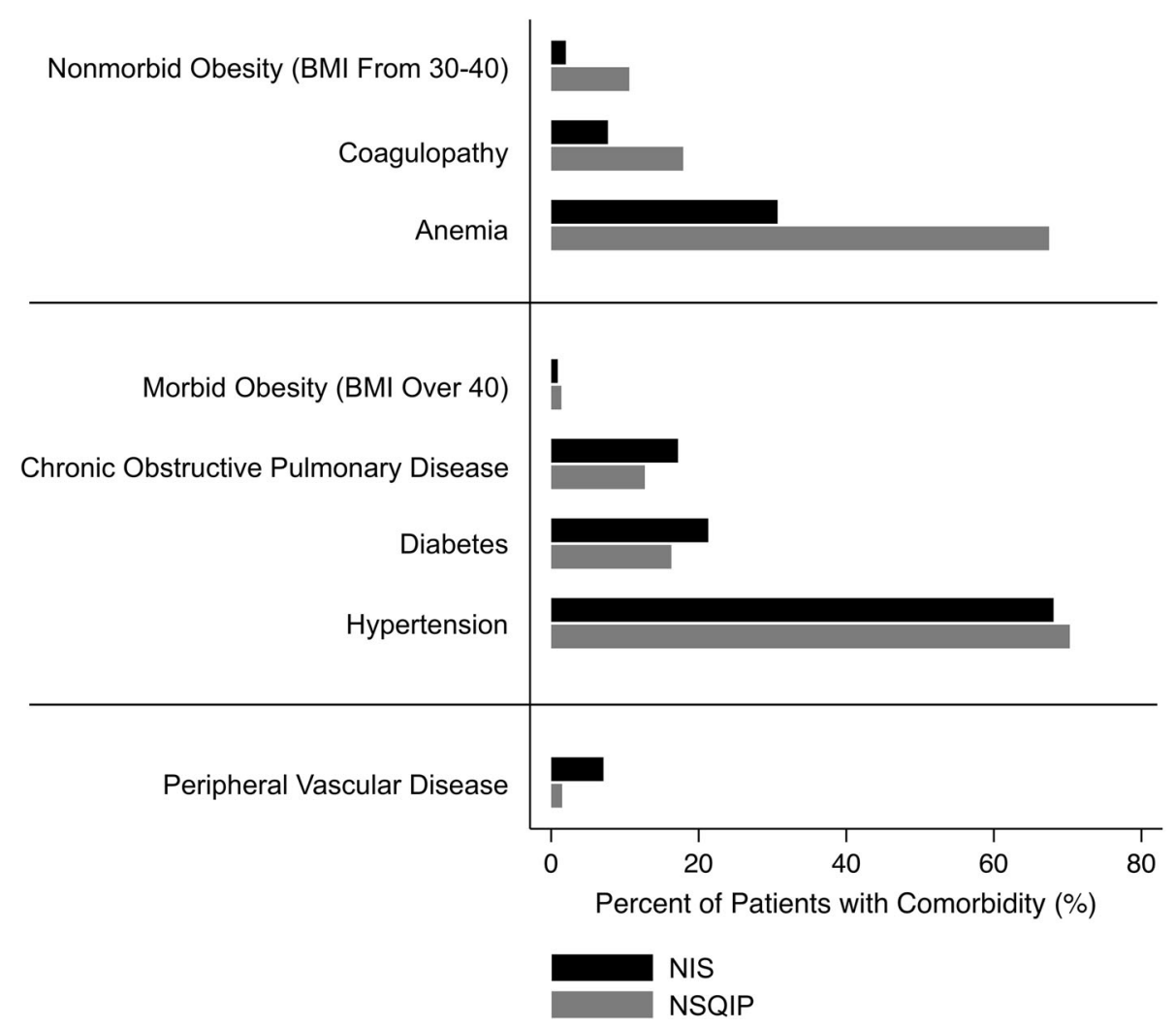

Fig. 4 For comorbidities shown in the upper $1 / 3$ the rate documented in the NSQIP was more than twice that in the NIS. For comorbidities shown in the lower $1 / 3$ the rate documented in the NIS was more than twice that in the NSQIP. In the middle $1 / 3$ the rates documented in the two databases were within a twofold difference of each other.

parameters. That is, because the ICD-9 codes in the NIS were selected by us to approximate NSQIP criteria, in some cases, these approximations may have been imperfect.

In this study, two cohorts undergoing the same orthopaedic procedure, each selected from national databases that use very different methods for data acquisition, were shown to have appropriately similar demographics and hospital lengths of stay. This indicates that the two databases can be used to identify similar populations of patients for studies of patients undergoing specific orthopaedic procedures.

With respect to comorbidities, the two databases documented prevalences that differed by more than twofold from each other for four of eight commonly studied comorbidities, including nonmorbid obesity, coagulopathy, anemia, and peripheral vascular disease. These findings raise concerns regarding the external validity of orthopaedic database research involving these comorbidities. For the analysis conducted in the NSQIP, the prevalence of nonmorbid obesity was determined from height and weight variables directly reported in the data set. In contrast, for the analysis conducted in the NIS, the prevalence was determined from ICD-9 codes. It appears that in many cases in which the height and weight of patients included in the NIS would have indicated obesity, obesity simply is not being coded for by hospitals and therefore is not documented in the NIS. Some orthopaedic publications using NIS have used ICD-9 codes to study obesity and are affected by this result $[6,7,9,15,17]$. Anemia showed a similar pattern and a similarly large number of NIS studies in orthopaedics may be affected [11, 13, 18]. Coagulopathy was documented just more than twice as often in the NSQIP as in the NIS. This difference may be because the NSQIP considers patients receiving chronic anticoagulation therapy to have "coagulopathy" if the anticoagulant is not discontinued before surgery (including any case in which there is not explicit documentation of anticoagulant discontinuation in the medical record) [2]. Coagulopathy in the NIS, however, was determined using the "cm_coag" comorbidity variable, which is based on an array of ICD-9 codes indicative of inherited or acquired coagulopathies that do not include anticoagulant therapy [1]. In this case, neither database is necessarily documenting patients more accurately than the other; investigators should merely be aware of this difference in definitions when conducting and interpreting research. Finally, the opposite pattern was observed for peripheral vascular disease with the prevalence in the NIS more than twice that in the NSQIP. It is 


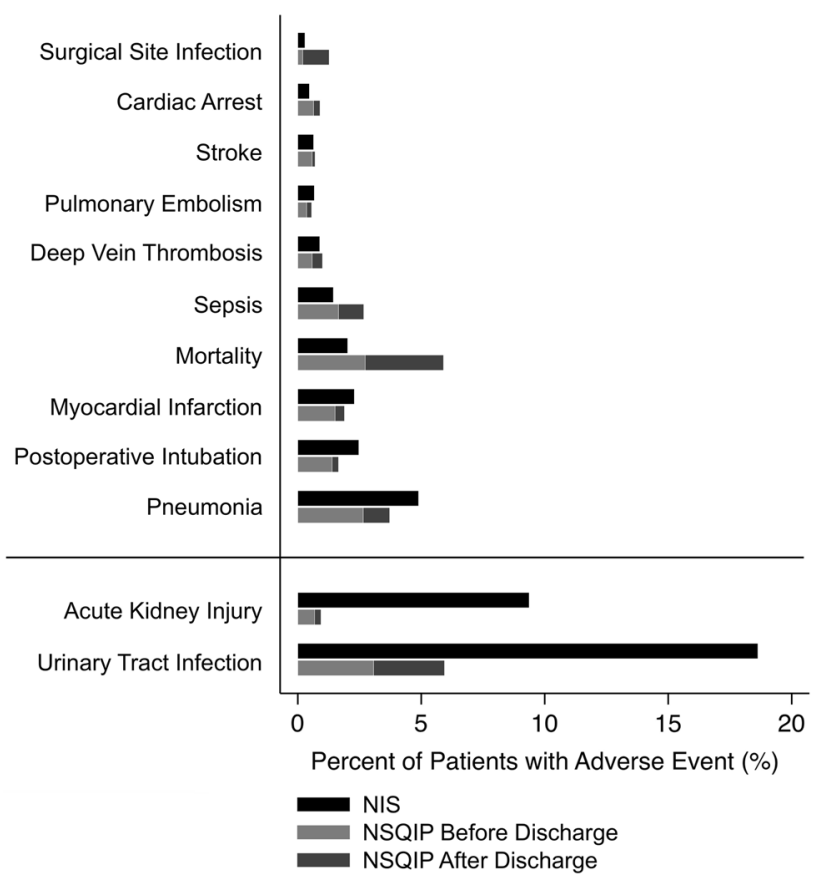

Fig. 5 For events shown in the lower $1 / 2$, the rate documented in the NIS was more than twice the rate documented in the NSQIP before discharge. For events shown in the upper $1 / 2$, the rate documented in the NIS and the rate documented in the NSQIP before discharge were within a twofold difference of each other. For the NSQIP, the percent of patients with adverse events after discharge can be added to the percent of patients with adverse events before discharge to get the total rate of adverse events during the first 30 postoperative days.

not clear which database is performing more accurately. The interpretation of some orthopaedic studies may be affected [5, 11, 16, 17].

With respect to inpatient adverse events, the two databases documented similar frequencies of 10 of 12 commonly studied inpatient adverse events, supporting the validity of the NIS, NSQIP, and related databases for the study of these events. However, acute kidney injury and urinary tract infection before discharge were documented in more than twice as many patients in the NIS as in the NSQIP. This is most likely related to the strict criteria for documentation of these adverse events set by the NSQIP and the contrastingly more liberal ICD-9 coding used by the hospitals that contribute to the NIS. For example, in the NSQIP, urinary tract infection can be documented only if very specific criteria involving combinations of signs, symptoms, and laboratory results are clearly documented in the patient's chart [2]. In contrast, there are no such discrete guidelines in ICD-9 coding [4]. A patient may be categorized as having "urinary tract infection" (ICD-9 code 599.0) without having met any specific criteria. Similarly, specific criteria involving a minimum increase in creatinine and/or dialysis requirement are set for acute kidney injury in the NSQIP [2] that may not always be met when the ICD-9 code for acute kidney injury (584.x) is used [4]. Our data do not suggest that either system is performing more accurately than the other; however, that the NSQIP requires these specific criteria to be documented in the medical record likely explains why the frequencies documented in the NSQIP are lower than those in the NIS. Some recent studies may be affected by these findings $[10,11,14,16,19]$.

Although the rate documented in the NSQIP after discharge was low for some adverse events, this rate actually exceeded that documented in the NSQIP before discharge for surgical site infection and mortality. This finding highlights a limitation of the NIS, which contains data on patients only before discharge, to study these outcomes. That is, surgical site infection and mortality within 30 days of surgery are actually more likely to be missed by the NIS than to be documented by it. There are NIS studies that this observation affects $[5,13,17,19]$.

During 2009 to 2011, the years from which we drew data for this study, hospitals applied for reimbursement using ICD-9 codes. As a result, inpatient databases were coded using ICD-9 codes. However, the deadline for United States hospitals to adopt the newest form of the ICD, the ICDl-10, is October 1, 2014 [3]. As hospitals convert to the ICD-10, so too will the data that are available in the NIS. The ICD-10 code set is not a simple update of the ICD-9 code set [3]. There is a fundamental change in structure and concept, with the most important purpose to increase the specificity of the coding. For example, while in ICD-9 a burn on the left arm could not be differentiated from a burn on the right, with the ICD-10, these will have separate codes. The aim of these improvements is to increase specificity for reimbursement purposes, as it is helpful for payers to more clearly understand that there were two arms burned, not just one. However, the benefits for researchers will be significant as well. Whether having NIS data encoded in the ICD-10 format rather than ICD-9 would have changed the results of our study cannot be known; however, as discussed above, we posit that the discrepancy observed, for example, in obesity, is not an error of the specificity of the coding system, but more likely an error in the accuracy of coding practice.

As database studies become more common in orthopaedic surgery, authors, reviewers, and readers should pay careful attention to the sources of data from which study results are drawn. We found that two commonly used databases can be used to identify similar populations of orthopaedic patients. However, the databases document obesity, coagulopathy, anemia, peripheral vascular disease, acute kidney injury, and urinary tract infection at different rates, potentially affecting the interpretation of many orthopaedic studies [5-7, 9-11, 13-19]. Specifically, for example, many of these studies claim to identify "incidence 
and risk factors" ("incidence" often is casually acquainted to the term "frequency" used here) of various postoperative adverse events. We showed that these estimates of frequency can vary tremendously based on the database used; therefore, studies claiming to identify the frequency of adverse events should be interpreted with caution. The risk factor identification portions of these studies may or may not be more valid; our current study cannot address this. As a result of the inpatient-only nature of their data, the NIS and other ICD-9-based databases may capture only fractions of events occurring during the first 30 postoperative days. For this reason, the NSQIP is particularly well suited, and the NIS and other inpatient-only databases are particularly poorly suited, for studying events that occur late during the postoperative course (after discharge; surgical site infection and mortality in the case of hip fracture studies). Although we analyzed a majority of the adverse events available in the NSQIP database (those for which ICD-9 codes from the NIS could be appropriately matched), we analyzed only a small fraction of potentially available ICD-9 codes from the NIS. For this reason, the NIS is well suited for studying a wide range of rare postoperative adverse events that are not collected in the NSQIP-directed review of medical records.

\section{Appendix}

Appendix 1. Data elements from the NIS and NSQIP used to identify patients with comorbidities

\begin{tabular}{|c|c|c|}
\hline Comorbidity & NIS ICD-9 code(s) or 'variables' (descriptions)* & NSQIP ‘variables’ (descriptions) \\
\hline Anemia & $\begin{array}{l}\text { "cm_anemdef" (deficiency anemia) } \\
\text { "cm_bldloss" (chronic blood loss anemia) }\end{array}$ & "prhct" (preoperative hematocrit) ${ }^{\dagger}$ \\
\hline Chronic obstructive pulmonary disease & $\begin{array}{l}\text { 491.xx (chronic bronchitis) } \\
492 . x \text { (emphysema) } \\
496 \text { (chronic airway obstruction) }\end{array}$ & $\begin{array}{c}\text { "hxcpod" (history of severe chronic } \\
\text { obstructive pulmonary disease) }\end{array}$ \\
\hline Coagulopathy & "cm_coag" (coagulopathy) & "bleeddis" (bleeding disorders) \\
\hline Diabetes & $\begin{array}{l}\text { "cm_dm" (diabetes, uncomplicated) } \\
\text { "cm_dmcx (diabetes, with chronic complications) }\end{array}$ & $\begin{array}{l}\text { "diabetes" (diabetes mellitus with oral } \\
\text { agents or insulin) }\end{array}$ \\
\hline Hypertension & “cm_htn_c" (hypertension) & $\begin{array}{l}\text { "hypermed" (hypertension requiring } \\
\text { medication) }\end{array}$ \\
\hline Morbid obesity & $\begin{array}{l}\left.278.01 \text { (morbid obesity [BMI over } 40 \mathrm{~kg} / \mathrm{m}^{2}\right] \text { ) } \\
\left.\text { V85.3 (morbid obesity [BMI over } 40 \mathrm{~kg} / \mathrm{m}^{2}\right] \text { ) }\end{array}$ & $\begin{array}{l}\text { "height" (height) } \\
\text { "weight" (weight) }{ }^{*}\end{array}$ \\
\hline Nonmorbid obesity & $\begin{array}{l}\left.278.00 \text { (obesity [BMI from } 30-40 \mathrm{~kg} / \mathrm{m}^{2}\right] \text { ) } \\
\left.\text { V85.4 (obesity [BMI from } 30-40 \mathrm{~kg} / \mathrm{m}^{2}\right] \text { ) }\end{array}$ & $\begin{array}{l}\text { "height" (height) } \\
\text { "weight" (weight) }{ }^{\S}\end{array}$ \\
\hline Peripheral vascular disease & "cm_perivasc" (peripheral vascular disorder) & $\begin{array}{l}\text { "hxpvd" (history of revascularization/ } \\
\text { amputation) } \\
\text { "restpain" (rest pain/gangrene) }\end{array}$ \\
\hline
\end{tabular}

* Data elements used in the NIS were ICD-9 codes or directly reported comorbidity variables (variables starting with "cm_"). The directly reported comorbidity variables are summaries of ICD-9 codes using a proprietary algorithm. " $\mathrm{x}$ " is a wildcard digit (can be from 0 to 9 ); ${ }^{\dagger}$ the patient was considered to have anemia if the preoperative hematocrit (variable named "prhct") was $<41$ for males or $<36$ for females; the patient was considered to have morbid obesity if $703 *$ (weight/[height*height]) was $>40 ;{ }^{\circledR}$ the patient was considered to have nonmorbid obesity if $703 *$ (weight/[height*height]) was between 30 and 40; NIS = Nationwide Inpatient Sample; NSQIP = National Surgical Quality Improvement Program; ICD-9 $=$ International Classification of Diseases, $9^{\text {th }}$ Revision.

Appendix 2. Data elements from the NIS and NSQIP used to identify patients with adverse events

\begin{tabular}{|c|c|c|}
\hline Adverse event & NIS ICD-9 codes or 'variables' (descriptions)* & NSQIP ‘variables’ (descriptions) \\
\hline Acute kidney injury & 584.x (acute kidney failure) & $\begin{array}{l}\text { "noprenafl" (acute renal failure, postoperative) } \\
\text { "nrenainsf" (progressive renal insufficiency, postoperative) }\end{array}$ \\
\hline Cardiac arrest & $\begin{array}{l}427.5 \text { (cardiac arrest) } \\
427.41 \text { (ventricular fibrillation) }\end{array}$ & $\begin{array}{l}\text { "ncdarrest" (cardiac arrest requiring cardiopulmonary } \\
\text { resuscitation, postoperative) } \\
\text { "typeintoc" (cardiac arrest requiring cardiopulmonary } \\
\text { resuscitation, intraoperative) }\end{array}$ \\
\hline Death & "died" (death) & "death" (death) \\
\hline
\end{tabular}


Appendix 2. continued

\begin{tabular}{|c|c|c|}
\hline Adverse event & NIS ICD-9 codes or 'variables' (descriptions)* & NSQIP ‘variables’ (descriptions) \\
\hline Deep vein thrombosis & $\begin{array}{l}453.2 \text { (venous embolism and thrombosis of the } \\
\text { inferior vena cava) } \\
453.3 \text { (venous embolism and thrombosis of the renal } \\
\text { vein) } \\
453.4 x \text { (acute venous embolism and thrombosis of } \\
\text { unspecified deep vessels of lower extremity) } \\
453.82 \text { (acute venous embolism and thrombosis of } \\
\text { deep veins of upper extremity) } \\
453.84 \text { (acute venous embolism and thrombosis of } \\
\text { axillary veins) } \\
453.85 \text { (acute venous embolism and thrombosis of } \\
\text { subclavian veins) } \\
453.86 \text { (acute venous embolism and thrombosis of } \\
\text { internal jugular veins) }\end{array}$ & $\begin{array}{l}\text { "nothdvt" (deep vein thrombosis, with or without } \\
\text { inflammation, postoperative) }\end{array}$ \\
\hline Myocardial infarction & 410.xx (acute myocardial infarction) & $\begin{array}{l}\text { "ncdmi" (myocardial infarction, postoperative) } \\
\text { "typeintoc" (myocardial infarction, intraoperative) }\end{array}$ \\
\hline Pneumonia & $\begin{array}{l}\text { 480.x (viral pneumonia) } \\
481 \text { (pneumococcal pneumonia) } \\
482 . x x \text { (other bacterial pneumonia) } \\
\text { 483.x (pneumonia resulting from other specified } \\
\quad \text { organism) } \\
\text { 484.x (pneumonia in infectious diseases classified } \\
\quad \text { elsewhere) } \\
485 \text { (bronchopneumonia, organism unspecified) } \\
486 \text { (pneumonia, organism unspecified) }\end{array}$ & “noupneumo" (pneumonia, postoperative) \\
\hline Pulmonary embolism & 415.1 (pulmonary embolism and infarction) & "npulembol" (pulmonary embolism, postoperative) \\
\hline Sepsis & $\begin{array}{l}\text { 038.xx (septicemia) } \\
112.5 \text { (disseminated candidiasis) } \\
785.52 \text { (septic shock) } \\
995.91 \text { (sepsis) } \\
995.92 \text { (severe sepsis) }\end{array}$ & $\begin{array}{l}\text { "nothsysep" (sepsis, postoperative) } \\
\text { "nothseshock" (septic shock, postoperative) }\end{array}$ \\
\hline Stroke & $\begin{array}{l}997.02 \text { (iatrogenic cerebrovascular infarction or } \\
\text { hemorrhage) } \\
430 \text { (subarachnoid hemorrhage) } \\
431 \text { (intracerebral hemorrhage) } \\
433.01 \text { (occlusion and stenosis of precerebral } \\
\text { arteries with cerebral infarction) } \\
433.11 \text { (occlusion and stenosis of carotid artery with } \\
\text { cerebral infarction) } \\
433.21 \text { (occlusion and stenosis of vertebral artery } \\
\text { with cerebral infarction) } \\
433.31 \text { (occlusion and stenosis of multiple and } \\
\text { bilateral precerebral arteries with cerebral } \\
\text { infarction) } \\
433.81 \text { (occlusion and stenosis of other specified } \\
\text { precerebral artery with cerebral infarction) } \\
433.91 \text { (occlusion and stenosis of unspecified } \\
\text { precerebral artery with cerebral infarction) } \\
434.01 \text { (cerebral thrombosis with cerebral } \\
\text { infarction) } \\
434.11 \text { (cerebral embolism with cerebral infarction) } \\
434.91 \text { (cerebral artery occlusion, unspecified with } \\
\text { cerebral infarction) }\end{array}$ & "ncnscva" (stroke/cerebrovascular accident, postoperative) \\
\hline
\end{tabular}


Appendix 2. continued

\begin{tabular}{|c|c|c|}
\hline Adverse event & NIS ICD-9 codes or 'variables' (descriptions)* & NSQIP ‘variables’ (descriptions) \\
\hline Surgical site infection & $\begin{array}{l}\text { 998.5x (postoperative infection not elsewhere } \\
\text { classified) } \\
996.67 \text { (infection and inflammatory reaction } \\
\text { resulting from other internal orthopaedic device, } \\
\text { implant, or graft) }\end{array}$ & $\begin{array}{l}\text { "nsupinfec" (superficial surgical site infection, } \\
\text { postoperative) } \\
\text { "nwndinfd" (deep surgical site infection, postoperative) } \\
\text { "norgspcssi" (organ/space surgical site infection, } \\
\text { postoperative) }\end{array}$ \\
\hline Postoperative intubation & $\begin{array}{l}96.01 \text { (insertion of nasopharyngeal airway) } \\
96.02 \text { (insertion of oropharyngeal airway) } \\
96.03 \text { (insertion of esophageal obturator airway) } \\
96.04 \text { (insertion of endotracheal tube) } \\
96.05 \text { (other intubation of respiratory tract) } \\
\text { 96.7x (other continuous invasive mechanical } \\
\text { ventilation) }\end{array}$ & $\begin{array}{l}\text { "nreintub" (unplanned intubation, postoperative) } \\
\text { "nfailwean" (on ventilator more than } 48 \text { hours, } \\
\text { postoperative) }\end{array}$ \\
\hline Urinary tract infection & 599.0 (urinary tract infection) & "nurninfec" (urinary tract infection, postoperative) \\
\hline
\end{tabular}

* " $\mathrm{x}$ " is a wildcard digit (can be from 0 to 9); NIS = Nationwide Inpatient Sample; NSQIP = National Surgical Quality Improvement Program; ICD-9 = International Classification of Diseases, $9^{\text {th }}$ Revision.

\section{References}

1. Agency for Healthcare Research and Quality. Healthcare Cost and Utilization Project (HCUP). Introduction to the HCUP Nationwide Inpatient Sample 2011. Available at: http://www. hcup-us.ahrq.gov. Accessed December 1, 2013.

2. American College of Surgeons. National Surgical Quality Improvement Program. User Guide for the 2011 Participant Use Data File. Available at: http://www.acsnsqip.org. Accessed December 1, 2013.

3. American Medical Assocation. Preparing for the ICD-10 Code Set: The Differences Between ICD-9 and ICD-10. Available at: http://www.ama-assn.org/resources/doc/washington/icd10-icd9differences-fact-sheet.pdf. Accessed February 22, 2014.

4. Buck CJ. 2011 ICD-9-CM for Hospitals, Professional Edition. Volumes 1-3. St Louis, MO: Saunders; 2011.

5. D'Apuzzo MR, Pao AW, Novicoff WM, Browne JA. Age as an independent risk factor for postoperative morbidity and mortality after total joint arthroplasty in patients 90 years of age or older. J Arthroplasty. 2014;29:477-480.

6. Gonzalez Della Valle A, Chiu YL, Ma Y, Mazumdar M, Memtsoudis SG. The metabolic syndrome in patients undergoing knee and hip arthroplasty: trends and in-hospital outcomes in the United States. J Arthroplasty. 2012;27:1743-1749.e1.

7. Kalanithi PA, Arrigo R, Boakye M. Morbid obesity increases cost and complication rates in spinal arthrodesis. Spine (Phila $\mathrm{Pa}$ 1976). 2012:37:982-988.

8. Khuri SF. The NSQIP: a new frontier in surgery. Surgery. 2005;138:837-843.

9. Losina E, Thornhill TS, Rome BN, Wright J, Katz JN. The dramatic increase in total knee replacement utilization rates in the United States cannot be fully explained by growth in population size and the obesity epidemic. J Bone Joint Surg Am. 2012;94:201-207.

10. Marchant MH Jr, Viens NA, Cook C, Vail TP, Bolognesi MP. The impact of glycemic control and diabetes mellitus on perioperative outcomes after total joint arthroplasty. J Bone Joint Surg Am. 2009;91:1621-1629.

11. Martin CT, Pugely AJ, Gao Y, Wolf BR. Risk factors for thirtyday morbidity and mortality following knee arthroscopy: a review of 12,271 patients from the National Surgical Quality Improvement Program database. J Bone Joint Surg Am. 2013;95:e98 $1-10$.

12. Moverley R, Rankin KS, McNamara I, Davidson DJ, Reed M, Sprowson AP. Impact factors of orthopaedic journals between 2000 and 2010: trends and comparisons with other surgical specialties. Int Orthop. 2013;37:561-567.

13. Nikkel LE, Fox EJ, Black KP, Davis C, Andersen L, Hollenbeak CS. Impact of comorbidities on hospitalization costs following hip fracture. J Bone Joint Surg Am. 2012;94:9-17.

14. O’Malley NT, Fleming FJ, Gunzler DD, Messing SP, Kates SL. Factors independently associated with complications and length of stay after hip arthroplasty: analysis of the National Surgical Quality Improvement Program. J Arthroplasty. 2012;27:1832-1837.

15. Odum SM, Springer BD, Dennos AC, Fehring TK. National obesity trends in total knee arthroplasty. $J$ Arthroplasty. 2013;28(8 suppl):148-151.

16. Pugely AJ, Martin CT, Gao Y, Klocke NF, Callaghan JJ, Marsh JL. A risk calculator for short-term morbidity and mortality after hip fracture surgery. J Orthop Trauma. 2014;28:63-69.

17. Rasouli MR, Maltenfort MG, Ross D, Hozack WJ, Memtsoudis SG, Parvizi J. Perioperative morbidity and mortality following bilateral total hip arthroplasty. J Arthroplasty. 2014;29:142-148.

18. Seicean A, Seicean S, Alan N, Schiltz NK, Rosenbaum BP, Jones PK, Kattan MW, Neuhauser D, Weil RJ. Preoperative anemia and perioperative outcomes in patients who undergo elective spine surgery. Spine (Phila Pa 1976). 2013;38:1331-1341.

19. Shah SN, Wainess RM, Karunakar MA. Hemiarthroplasty for femoral neck fracture in the elderly surgeon and hospital volumerelated outcomes. J Arthroplasty. 2005;20:503-508. 